\title{
Winter energetics of female Indiana bats Myotis sodalis
}

K. M. Day

MSU Graduate Student

Thomas Tomasi

Missouri State University

Follow this and additional works at: https://bearworks.missouristate.edu/articles-cnas

\section{Recommended Citation}

Day, Katie M., and Thomas E. Tomasi. "Winter energetics of female Indiana bats Myotis sodalis." Physiological and Biochemical Zoology 87, no. 1 (2014): 56-64.

This article or document was made available through BearWorks, the institutional repository of Missouri State University. The work contained in it may be protected by copyright and require permission of the copyright holder for reuse or redistribution.

For more information, please contact BearWorks@library.missouristate.edu. 


\section{Winter Energetics of Female Indiana Bats Myotis sodalis}

\author{
Katie M. Day ${ }^{\dagger}$ \\ Thomas E. Tomasi \\ Department of Biology, Missouri State University, \\ Springfield, Missouri 65897
}

Accepted 5/20/2013; Electronically Published 8/7/2013

\begin{abstract}
Understanding physiological limits and environmental optima is critical to developing protection strategies for endangered and threatened species. One theory to explain the decline in endangered Indiana bat Myotis sodalis populations involves increasing cave temperatures in winter hibernacula. Altered cave temperatures can raise metabolism and cause more arousals in torpid bats, both of which use more fat reserves. In addition, fluctuations in cave temperatures may cause additional arousals. Our objectives were to quantify the effect of temperature and fluctuations thereof on torpid metabolism and arousal frequency in this species. Female Indiana bats $(n=36)$ were collected from caves just before hibernation, maintained in an environmental chamber that simulated hibernacula conditions, and had skin temperature recorded every $30 \mathrm{~min}$ throughout the winter. One environmental chamber containing bats $(n=12)$ was sequentially set at $8^{\circ}, 6^{\circ}$, and $4^{\circ} \mathrm{C}$ over the winter. The second chamber containing bats $(n=12)$ experienced the same mean temperatures, but temperature fluctuated $\pm 2{ }^{\circ} \mathrm{C}$ on a regular basis. Torpor bouts were longest at $4^{\circ} \mathrm{C}$ and were not affected by temperature fluctuations. However, the temperature fluctuations appeared to cause longer arousals. Other bats $(n=12)$ were individually placed in metabolic chambers to calculate oxygen consumption during torpor and during arousals. Torpid metabolism was affected by temperature; at $9^{\circ} \mathrm{C}$, it was higher than at $7^{\circ}$ or $5^{\circ} \mathrm{C}$. Metabolism during arousals was not different among temperature treatments, but rates were almost 200 times higher than torpid metabolic rates. We calculated a winter energy budget and, from the energetic perspective, determined an optimum hibernation temperature $\left(3^{\circ}-6^{\circ} \mathrm{C}\right)$ for female Indiana bats. These findings suggest that hibernacula that provide these conditions deserve extra protection, although other factors in addition to energetics may play a role in temperature preferences.
\end{abstract}

\footnotetext{
* This paper was submitted in response to a call for papers for a Focused Issue on "Conservation Physiology."

$\dagger$ Corresponding author. Present address: Ecology and Environment, Chicago, Illinois 60603; e-mail: kday@ene.com.
}

Physiological and Biochemical Zoology 87(1):56-64. 2014. (C) 2013 by The University of Chicago. All rights reserved. 1522-2152/2014/8701-2108\$15.00. DOI: $10.1086 / 671563$

\section{Introduction}

For endotherms, maintaining a constant high body temperature $\left(T_{\mathrm{B}}\right)$ requires considerable energetic investment. In winter, food abundance in temperate regions typically diminishes, providing an additional energetic challenge. In response to this challenge, insectivorous bats can either migrate to areas with warmer temperatures or employ torpor (Geiser 2004). For the latter, many species of temperate bats migrate in the fall to hibernate (seasonal torpor) in suitable caves, mines, or other structures. While in torpor, the energy used (and thus fat reserves) is dependent on the ambient temperature $\left(T_{\mathrm{A}}\right)$.

Like other hibernating mammals, bats naturally arouse during the hibernation season for reasons still not clearly understood (Willis 1982; Carey 1993), and these arousals are energetically expensive. In little brown bats Myotis lucifugus, one arousal is estimated to be energetically equivalent to approximately $65 \mathrm{~d}$ of hibernation (Thomas et al. 1990). The frequency of arousals also appears to be temperature dependent (Twente et al. 1985; Barnes and Ritter 1993; Nicol et al. 2004). Therefore, an energetically optimum temperature should exist at which hibernating bats have the lowest energy requirements (metabolic rate during torpor plus arousal costs; Twente 1955).

For years, ecologists have debated whether animals minimize energy expenditure (and therefore minimize the need for food) or maximize energy intake (matching expenditure to this food intake). For hibernation biologists, the analogous dilemma is whether hibernators maximize the use of torpor to conserve energy for other purposes or minimize torpor use and try to function physiologically as close to "normal" as available energy will support, to decrease the negative physiological and ecological costs of hibernation (hibernation optimization; Humphries et al. 2003). These nonenergetic costs may involve functions normally suppressed during torpor, such as the immune system (Bouma et al. 2010), osmoregulation (Speakman and Racey 1989; Thomas and Cloutier 1992), memory consolidation (Weltzin et al. 2006; Arant et al. 2011), non-REM sleep (Heller et al. 1993), or other metabolic activities (Willis 1982; Humphries et al. 2003). Leaner bats could spend more time at temperatures that provide the lowest energetic costs, whereas fatter bats can afford to arouse more often (Humphries et al. 2003 ) or stay aroused longer. No resolution of this debate is likely to cover all species and all situations, but Boyles and colleagues (2007) suggest that North American bats are torpor minimizers and will select a hibernaculum temperature warmer than the energetically optimal temperature if they have sufficient stored fat reserves.

Most female insectivorous bats in temperate regions need energy for posthibernation migration to maternity roosts before 
food is abundant. In addition, fat reserves in female bats after hibernation may contribute to their reproductive success (Kunz et al. 1998). On the basis of these considerations, one can predict that females may use torpor more often than males, but this has not been systematically investigated. Understanding the winter hibernation energy budget (torpor plus arousals for the hibernation season) and how this varies with hibernaculum $T_{\mathrm{A}}$ is an important consideration for the conservation of endangered species that hibernate.

The Indiana bat Myotis sodalis is an insectivorous bat widely distributed across the eastern United States (Reid 2006), and it generally hibernates from October to March. The majority of Indiana bats currently hibernate in 23 priority-one hibernacula (each containing $\geq 10,000$ bats), located in seven US states (US Fish and Wildlife Service [USFWS] 2007). During 1965-2005, populations of hibernating Indiana bats decreased by $48 \%$ nationally (USFWS 2007 ), although more recent surveys (from 2001-2007) have indicated that the population was increasing (USFWS 2011). However, this trend has not been true for Missouri populations, where despite hibernacula protection since the 1970s, numbers appear to have decreased by 95\% during 1979-2007 (Elliott 2008).

These population decreases were in spite of the Indiana bat being listed in 1967 as an endangered species by the USFWS. Factors proposed to have contributed to the decline of the species include degradation of summer habitat (USFWS 2007), human disturbance of hibernating bats (Thomas 1995; USFWS 2007), improper gating or closing of cave entrances (Richter et al. 1993), pesticides (O'Shea and Clark 2002; USFWS 2007), and most recently white-nose syndrome (Blehert et al. 2009). Since the discovery of white-nose syndrome in 2006 (Turner et al. 2011), winter census data from 42 northeastern US hibernacula found a $75 \%$ population decrease for Indiana bats.

Indiana bats prefer winter hibernacula temperatures of $3^{\circ}-$ $6^{\circ} \mathrm{C}$ and a relative humidity of $70 \%-100 \%$ (Humphrey 1978 ; Tuttle and Kennedy 2002). Previous laboratory work on the hibernation energetics of male Indiana bats indicates that their optimum temperature for torpor is $5^{\circ} \mathrm{C}$ (Dzurick and Tomasi 2008). In addition, individuals hibernating at $5^{\circ}$ and $7^{\circ} \mathrm{C}$ had the fewest arousals (Dzurick and Tomasi 2008).

Changes in air flow in the cave, whether natural or anthropogenic (intentional or accidental), can impact the cave temperature. In addition, when the mean winter $T_{\mathrm{A}}$ surrounding the cave changes, such as predicted with global climate change, cave temperature and humidity may also change. Cumulatively, these anthropogenically induced changes can adversely influence the physiology of bats during hibernation, adding stress to an already challenging situation. Gathering information on the metabolic response of bats during hibernation to various temperatures will aid conservation agencies in predicting population changes attributable to future climate change, which has been suggested to affect hibernation in other mammals (Nemeth 2012; Pretzlaff and Dausmann 2012).

In this regard, Humphries and colleagues (2002) suggest that, in the next $80 \mathrm{yr}$, little brown bats will hibernate in more northern latitudes. Recent census data (2001-2005) show In- diana bat populations moving more northward in their winter range, compared with numbers from the 1960s and 1970s (USFWS 2007). Consistent with this, a new northern Missouri mine has recently been discovered that may be the largest known Indiana bat hibernaculum (A. Elliot, personal communication).

Because sex differences in energetic strategies and requirements have been noted in other bats (Kurta and Kunz 1988; Cryan 2003; Jonasson and Willis 2011), and because Indiana bats have sex-specific roosting (presumably thermal) requirements in the summer (Timpone 2004), our primary objective was to calculate a winter energy budget for female Indiana bats (and compare it with that for males, based on other published data). In addition, because periodic temperature fluctuations aboveground can alter cave temperature (Elliott and Clawson 2001), and the stability of the $T_{\mathrm{A}}$ in a hibernaculum may impact the bats' use of torpor, we investigated the effect of fluctuating temperature on the energy budget of females. Determining the energetically optimal temperature for winter roost sites, in conjunction with information on body condition and the ecological and physiological costs of hibernation, will give conservation agencies insight into which caves or mines are providing the right conditions and therefore deserve extra protection.

\section{Material and Methods}

\section{Animal Capture and Care}

In October and early November 2006, 36 adult female Indiana bats were collected from Copper Hollow Sinkhole (Franklin County) and Great Scott Cave (Washington County) in Missouri and from a Unimin Minerals mine (Alexander County) in Illinois. Bats were collected with a harp trap placed in front of the caves or captured by hand in the mine. Permits for this work were obtained from the USFWS (TE096410-1), Missouri Department of Conservation (13184), and Missouri Department of Natural Resources. In addition, the project was approved by the Missouri State University Institutional Animal Care and Use Committee (2006-P).

Once in the laboratory, bats were placed in a modified $40 \times 40 \times 36-\mathrm{cm}$ nylon mesh cage (Apogee Industries) at room temperature and were hand fed water and vitaminenriched mealworms (adapted from Lollar and Schmidt-French 1998). After a few days, bats had learned to pick up mealworms and water from bowls hung inside the cages.

Before being placed into the environmental chambers for hibernation, all 36 bats had an iBBat temperature-sensitive data logger (Alpha Mach) temporarily attached to their backs with Skin-Bond (Smith and Nephew) to record skin temperature $\left(T_{\mathrm{SK}}\right)$ every $30 \mathrm{~min}$ throughout the winter. Bats were then divided into three treatment groups $(n=12$ each). The first two groups (temperature-stability treatments) were housed in $42 \times 76 \times 122-\mathrm{cm}$ nylon mesh cages (Apogee Industries) and placed in environmental chambers (Powers Scientific) where they were allowed to hibernate undisturbed for 4 mo. Water dishes with marbles (to prevent drowning) were placed in each environmental chamber, because Indiana bats are reported to 
drink during arousals (Hall 1962; Myers 1964). These chambers were maintained at constant temperatures, and relative humidity was maintained at $80 \%-90 \%$ by installing a misting system equipped with a programmable water timer (L. R. Nelson). This system allowed us to keep the relative humidity high without opening chambers (potential disturbance) for the entire hibernation season.

\section{Determination of $\mathrm{T}_{S K}$}

One environmental chamber was set at temperatures $\pm 0.5^{\circ} \mathrm{C}$ of $8^{\circ}, 6^{\circ}$, and $4^{\circ} \mathrm{C}$ for 2,6 , and $7 \mathrm{wk}$, respectively, with these time periods estimated to allow for $4-5$ arousals per bat based on arousal frequency data for male Indiana bats (Dzurick and Tomasi 2008). The second environmental chamber experienced the same mean temperatures over the same timetable. However, the $T_{\mathrm{A}}$ was set to fluctuate $\pm 2^{\circ} \mathrm{C}$ on a regular basis $(12-24 \mathrm{~h}$ temperature deviations every 2-4 d; Day 2008) to simulate natural conditions with occasional temperature perturbations in caves caused by aboveground weather patterns.

In March 2007, after hibernation ceased, the iBBat data loggers were removed, and the bats were fed for approximately 2 wk before being returned to their respective caves or mine. Skin temperature data were downloaded from the data loggers to determine the duration of arousals and torpor bouts and the mean torpid temperatures. Data for individual bats were examined graphically for the entire hibernation season. Because the number of torpor bouts and arousals differed among bats, individual means for each variable were calculated at each $T_{\mathrm{A}}$ to avoid pseudoreplication.

Torpor bouts had to be at least $48 \mathrm{~h}$ long to be included in the analysis. Dixon's $Q$-test $\left(Q_{0.90}\right)$ was used to identify outliers in each set of torpor bouts before calculating the mean torpor bout duration for each bat and temperature, and these outliers were eliminated from additional calculations. Whether these outliers represented equipment failures, were artifacts of captivity, or were real but rare phenomena could not be determined, but they were not consistent with normal torpor cycles as regularly reported. Arousals had to be at least $2 \mathrm{~h}$ long (including a period of warming and cooling), be at least a $10^{\circ} \mathrm{C}$ change from the baseline $T_{\mathrm{SK}}$, and natural (not caused by the temperature change timetable) to be included in the analysis. Outliers in the arousal duration data set were identified $\left(Q_{0.90}\right)$ and eliminated from additional calculations.

\section{Determination of Metabolic Rate}

The third group of bats $(n=12)$ was housed in a smaller environmental chamber and used to determine metabolic rates during torpor $\left(\mathrm{MR}_{\mathrm{T}}\right)$ at $9^{\circ}, 7^{\circ}, 5^{\circ}, 3^{\circ}$, and $1^{\circ} \mathrm{C}$ and during arousals $\left(\mathrm{MR}_{\mathrm{A}}\right)$ at $9^{\circ}, 7^{\circ}, 5^{\circ}$, and $3^{\circ} \mathrm{C}$ over the winter (late November to mid-March). Metabolic rates were measured as oxygen consumption rates in open-flow $50-\mathrm{mL}$ metabolic chambers (flow rates $=$ torpor: $0.025-0.050 \mathrm{~L} / \mathrm{min}$; arousals: $0.220-0.230 \mathrm{~L} / \mathrm{min}$ ) placed in temperature-controlled Plexiglas boxes with excurrent air evaluated by oxygen analyzers (AEI
Technologies; Applied Electrochemistry: S-3A/I and S-3A/II) after removal of $\mathrm{CO}_{2}$ (soda lime) and $\mathrm{H}_{2} \mathrm{O}$ (silica gel), as previously described (Dunbar and Tomasi 2006; Dzurick and Tomasi 2008). Bats hibernating individually in these chambers had $\mathrm{MR}_{\mathrm{T}}$ determined and then were kept in the metabolic chambers for a maximum of $12 \mathrm{~d}$ or until an arousal occurred to calculate $\mathrm{MR}_{\mathrm{A}}$ (Day 2008).

Oxygen concentration data (corrected for standard temperature and pressure, dry) were used to calculate $\mathrm{MR}_{\mathrm{T}}$ and $\mathrm{MR}_{\mathrm{A}}$ (Withers 2001), which were then adjusted for body mass (Heusner 1985). Data for individual bats were examined graphically. When torpid, bats used an intermittent breathing pattern, with apnic periods (generally $10-45 \mathrm{~min}$ ) followed by a period of ventilation. Therefore, average oxygen consumption rates during torpor were calculated over three intermittent breathing cycles. Average oxygen consumption rates for arousals were calculated for the entire arousal. Data from bats that did not demonstrate regular torpor bouts or arousals cycles were eliminated. In addition, only bats for which metabolic data were obtained at each temperature were included in the (repeatedmeasures) statistical analysis (torpor: $n=6$; arousal: $n=5$ ).

Metabolic data and $T_{\mathrm{SK}}$ data were used to calculate a winter energy budget (WEB) as follows: WEB $=\left(\mathrm{MR}_{\mathrm{T}}\right)\left(H_{\mathrm{T}}\right)+$ $\left(\mathrm{MR}_{\mathrm{A}}\right)\left(H_{\mathrm{A}}\right)(A)$, with $\mathrm{MR}_{\mathrm{T}}=$ torpid metabolic rate $(\mathrm{kcal} / \mathrm{h})$, $H_{\mathrm{T}}=$ time spent torpid $(\mathrm{h}), \mathrm{MR}_{\mathrm{A}}=$ arousal metabolic rate (kcal/h), $H_{\mathrm{A}}=$ time spent in an arousal (h), and $A=$ number of arousals in one hibernation season.

The WEB was calculated for each base $T_{\mathrm{A}}$ (as if the bat had gone through the entire winter at either $4^{\circ}, 6^{\circ}$, or $8^{\circ} \mathrm{C}$ ) and represents one hibernation season $(150 \mathrm{~d})$. Because the $T_{\mathrm{A}}$ used for metabolic rates did not match that used for the $T_{\mathrm{SK}}$ data, metabolic rates at $1^{\circ} \mathrm{C}$ higher and lower were averaged when calculating the $\mathrm{MR}_{\mathrm{T}}$ and $\mathrm{MR}_{\mathrm{A}}$ for each WEB. Mean $H_{\mathrm{T}}, H_{\mathrm{A}}$, and $A$ were calculated from bats in the constant temperature chamber.

\section{Statistical Methods}

The effect of $T_{\mathrm{A}}$ on $\mathrm{MR}_{\mathrm{T}}$ and $\mathrm{MR}_{\mathrm{A}}$ was assessed using a oneway, repeated-measures ANOVA with Tukey test for pairwise comparisons. The effects of $T_{\mathrm{A}}$ and temperature-stability treatment on torpid $T_{\mathrm{SK}}$, torpor bout duration, and arousal duration were assessed using a two-way repeated-measures ANOVA. The interactions between temperature and temperature-stability treatment and between temperature and bat were calculated. If $T_{\mathrm{A}}$ was significant in this two-way ANOVA, a one-way ANOVA with Tukey test was run for pairwise comparisons. All conclusions are based on a Type I error rate of 0.05. All analyses were performed using the generalized linear model or regression procedures of Minitab, release 15 .

Studies involving endangered species necessitate small sample sizes, such that certain assumptions of parametric statistics are not met (normality and homogeneity of variance) even with transformed data. However, only parametric tests can perform analyses with multiple independent variables $\left(T_{\mathrm{A}}\right.$ and temperature-stability treatments) while simultaneously including 
repeated-measures procedures. Failure to do the latter presumes that the data are independent, and violation of this assumption is more serious. ANOVA is robust against deviations of normality and homogeneity of variance (Rao 1998; Quinn and Keough 2002).

\section{Results}

$T_{\mathrm{A}}$ had an effect on $\mathrm{MR}_{\mathrm{T}}$ (repeated-measures one-way ANOVA; $P=0.023)$. The $\mathrm{MR}_{\mathrm{T}}$ at $9^{\circ} \mathrm{C}$ was higher than at $7^{\circ}$ or $5^{\circ} \mathrm{C}$ (Tukey pairwise comparison; $P<0.05$; fig. 1). Temperature had no effect on $\mathrm{MR}_{\mathrm{A}}$ (repeated-measures one-way ANOVA; $P=$ 0.230; fig. 2).

$T_{\mathrm{A}}$ had an effect on average torpor bout duration (repeatedmeasures two-way ANOVA; $P<0.0005$ ), with females at $8^{\circ} \mathrm{C}$ exhibiting shorter torpor bout durations than females at $6^{\circ}$ or $4^{\circ} \mathrm{C}$ (Tukey pairwise comparison; $P<0.05$; fig. 3 ). There was also a significant interaction between temperature and the temperature-stability treatment $(P<0.0005)$, such that the duration of torpor bouts was higher for bats in the stable-temperature chamber than in the fluctuating-temperature chamber at $4^{\circ} \mathrm{C}$, but this was reversed at $6^{\circ} \mathrm{C}$ (fig. 3 ).

Arousals from torpor generally lasted $3.0-4.5 \mathrm{~h}$, and there was no effect of $T_{\mathrm{A}}$ on duration $(P=0.701$; fig. 4$)$. Bats in the fluctuating-temperature chamber had slightly longer arousals $(\overline{\mathrm{X}}=4.0$ vs. 3.6 ; repeated-measures two-way ANOVA; $P=$ 0.050; fig. 4). There was also a significant interaction between $T_{\mathrm{A}}$ and temperature-stability treatment $(P<0.0005)$, such that bats in the fluctuating-temperature chamber aroused for longer

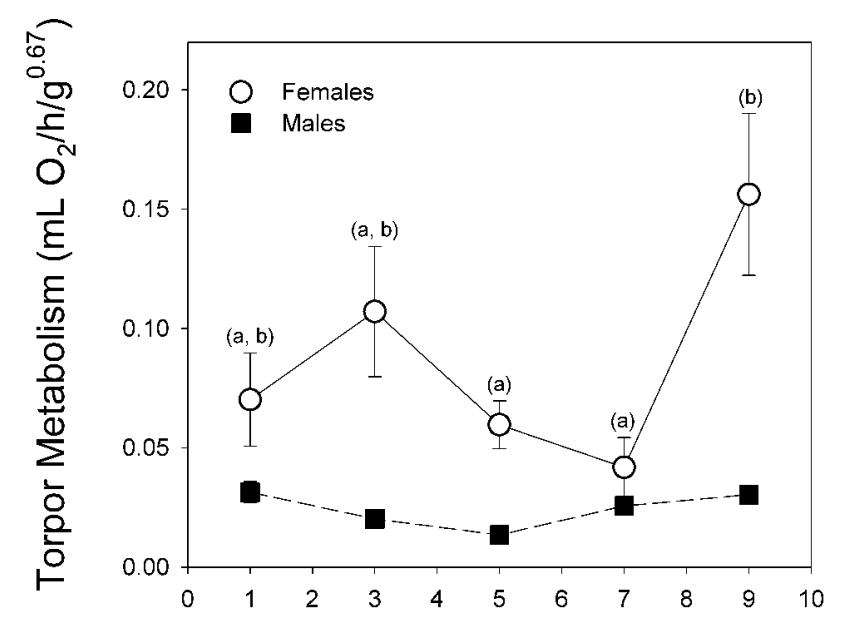

Ambient Temperature $\left({ }^{\circ} \mathrm{C}\right)$

Figure 1. Metabolism of torpid female Indiana bats at $1^{\circ}-9^{\circ} \mathrm{C}(n=$ 6). Ambient temperature had an effect on torpid metabolic rate (repeated-measures ANOVA; $P=0.023$ ). These torpid metabolic rates were higher at $9^{\circ} \mathrm{C}$ than at $7^{\circ}$ or $5^{\circ} \mathrm{C}$ (Tukey pairwise comparison; $P<0.05$; similarity in means are indicated with matching letters above the error bars). Analogous data for males are shown from Dzurick and Tomasi (2008) for comparison.

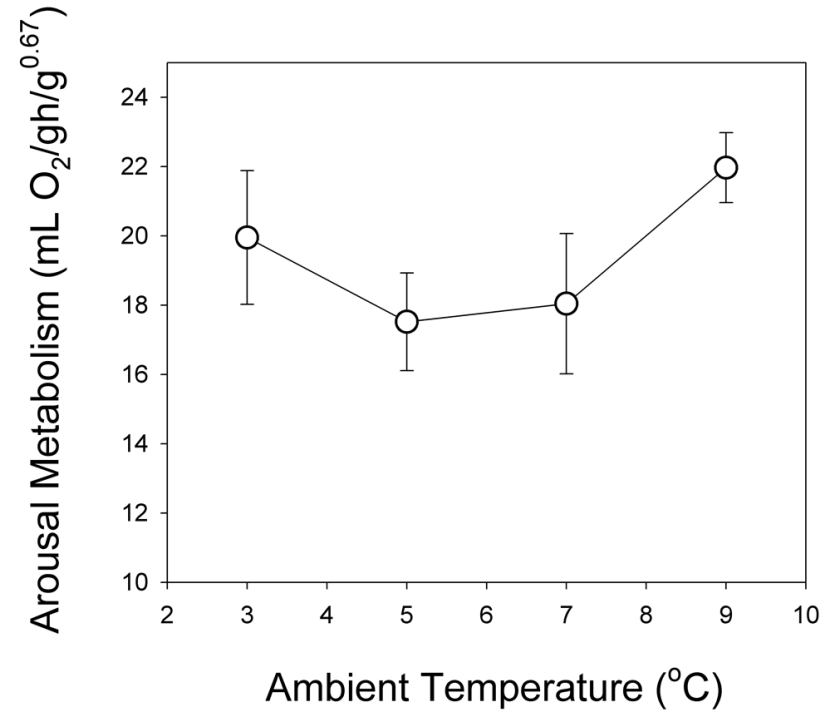

Figure 2. Metabolism during an arousal for female Indiana bats at $3^{\circ}-$ $9^{\circ} \mathrm{C}(n=5)$. Temperature had no effect on arousal metabolic rates (repeated-measures one-way ANOVA; $P=0.230$ ). Analogous data for males are not available.

than those in the constant-temperature chamber at $4^{\circ} \mathrm{C}$, but this was reversed at $6^{\circ} \mathrm{C}$.

As expected, $T_{\mathrm{SK}}$ in torpor was affected by $T_{\mathrm{A}}$ (repeatedmeasures two-way ANOVA; $P<0.0005)$, with colder bats at lower $T_{\mathrm{A}}$ (Tukey pairwise comparison; $P<0.05$ ). In addition, bats experiencing constant temperatures had higher $T_{\mathrm{SK}}$ (repeated-measures two-way ANOVA; $P=0.001$ ). Temperature and temperature-stability treatment had a significant interaction $(P<0.0005)$, presumably attributable to a smaller difference between temperature-stability treatments at $4^{\circ} \mathrm{C}$ than at warmer temperatures.

Our model calculations suggest that female Indiana bats expend less energy hibernating at temperatures of $4^{\circ} \mathrm{C}$ compared with $6^{\circ}$ or $8^{\circ} \mathrm{C}$ (table 1 ). This is due to short arousal durations and the longer torpor bout durations (i.e., fewer arousals) at $4^{\circ} \mathrm{C}$. If cave temperatures were to remain at $4^{\circ} \mathrm{C}$ for the entire hibernation season, female Indiana bats would use approximately one-third the amount of fat required if the temperature was to remain at $6^{\circ}$ or $8^{\circ} \mathrm{C}$ (table 1$)$.

\section{Discussion}

$\mathrm{MR}_{\mathrm{T}}$ for female Indiana bats is lowest at $5^{\circ}-7^{\circ} \mathrm{C}$ and 3-4 times higher at $9^{\circ} \mathrm{C}$ (fig. 1). This suggests that female Indiana bats with limited energy reserves should not choose hibernacula that hold a constant $T_{\mathrm{A}}$ of $9^{\circ} \mathrm{C}$, because it would cause them to use more energy and therefore potentially reduce their winter survival. Based on our WEB calculations (table 1), a hibernaculum at $8^{\circ} \mathrm{C}$ would require approximately $2.6 \mathrm{kcal}$ of additional energy, or almost $0.3 \mathrm{~g}$ of additional fat, to maintain the higher $\mathrm{MR}_{\mathrm{T}}$. Bats with this surplus energy reserve may choose to hibernate at the warmer $T_{\mathrm{A}}$ to minimize the physiological and 


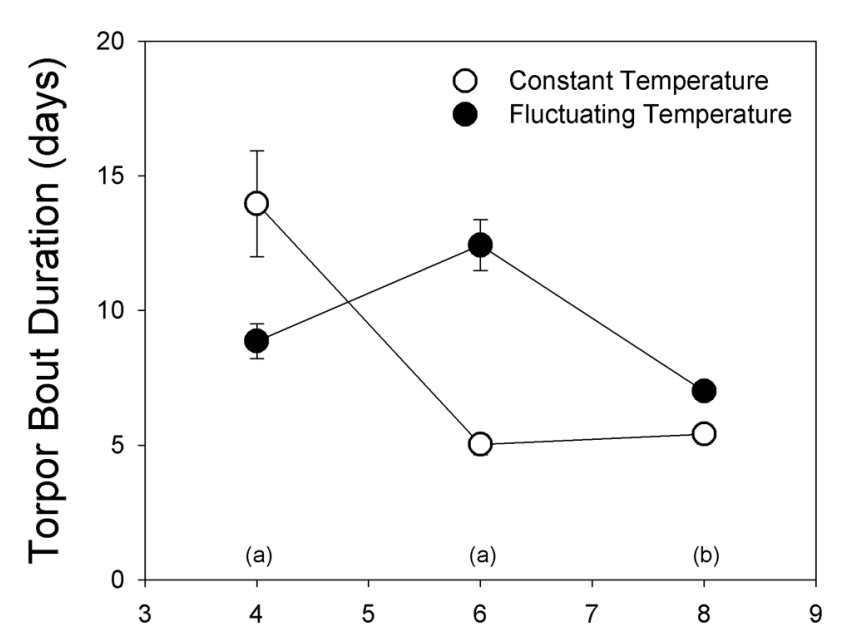

Ambient Temperature $\left({ }^{\circ} \mathrm{C}\right)$

Figure 3. Mean duration of torpor bouts for female Indiana bats at $4^{\circ}-8^{\circ} \mathrm{C}$ at fluctuating $(n=12)$ and constant $(n=7)$ temperature treatments. Temperature stability had no effect $(P=0.129)$. Ambient temperature had an effect on average torpor bout duration (repeatedmeasures two-way ANOVA; $P<0.0005)$, with bats at $8^{\circ} \mathrm{C}$ experiencing shorter torpor bout durations than bats at $6^{\circ}$ or $4^{\circ} \mathrm{C}$ (Tukey pairwise comparison; $P<0.05$; similarity in means [combined treatments] is indicated with matching letters above the temperatures).

ecological costs of hibernation, if this could be done without increasing the number of arousals over the winter.

Data from an early laboratory study found that the lowest $\mathrm{MR}_{\mathrm{T}}$ for Indiana bats occurs at $5^{\circ} \mathrm{C}$, when compared with $-5^{\circ}$ and $10^{\circ} \mathrm{C}$ (Henshaw 1965). This was confirmed with studies involving male Indiana bats in which the lowest $\mathrm{MR}_{\mathrm{T}}$ occurred at $5^{\circ} \mathrm{C}$, compared with $1^{\circ}, 3^{\circ}, 7^{\circ}$, and $9^{\circ} \mathrm{C}$ (Dzurick and Tomasi 2008). In contrast, the lowest $\mathrm{MR}_{\mathrm{T}}$ in our female Indiana bats occurred at $7^{\circ} \mathrm{C}$, although it was not statistically different from the $\mathrm{MR}_{\mathrm{T}}$ at $5^{\circ} \mathrm{C}$ (fig. 1).

At $1^{\circ} \mathrm{C}$, male Indiana bats exhibited two different strategies: some bats greatly increased $\mathrm{MR}_{\mathrm{T}}$, whereas other bats did not (Dzurick and Tomasi 2008). However, all females at this temperature exhibited lower-than-expected $\mathrm{MR}_{\mathrm{T}}$. This suggests that female Indiana bats may be more tolerant of colder temperatures than male bats. If energetic needs in the spring for females (migration and reproduction) are higher than for males, conserving energy at $1^{\circ} \mathrm{C}$ may be important, even if it increases the risk of freezing.

Unexpectedly, female Indiana bats show two to three times higher overall $\mathrm{MR}_{\mathrm{T}}$ at each $T_{\mathrm{A}}$ compared with male Indiana bats (Dzurick and Tomasi 2008). We expected similar or lower metabolic rates in females because of the higher posthibernation reproductive demands. This difference could be an artifact of male and female Indiana bat studies being conducted in two different winter seasons with the same equipment but using slightly different methodology. Although few studies compare the sexes in hibernation, female big brown bats Eptesicus fuscus tended to have higher (nonsignificant) torpid metabolic rates (M. Dunbar, personal communication). There may be some biological reason related to reproduction for females to keep higher $\mathrm{MR}_{\mathrm{T}}$ (and possibly higher $T_{\mathrm{B}}$, although data to test this are lacking). Females may need higher metabolic rates to keep stored sperm viable. There has been no investigation of sexspecific differences in $\mathrm{MR}_{\mathrm{T}}$ in bats or specific reproductive requirements for hibernating female bats during hibernation. However, Jonasson and Willis (2011) found adult female little brown bats were in significantly better body condition during the winter than adult males, which suggests the presence of a selective pressure for reproductive females to maintain a higher body mass.

$T_{\mathrm{SK}}$ data from the iBBat data loggers revealed that female Indiana bats exhibited longer torpor bouts with decreasing temperatures. Although the physiological need for periodic arousals is not well understood, this inverse relationship is common in bats and other hibernators (French 1982; Twente et al. 1985; Geiser and Kenagy 1988). On average, female Indiana bats exhibited torpor bout durations of approximately $10 \mathrm{~d}$ at $4^{\circ}-6^{\circ} \mathrm{C}$. This was slightly shorter than the 12.5 -d torpor bouts seen in male Indiana bats at $5^{\circ}-7^{\circ} \mathrm{C}$ (Dzurick and Tomasi 2008), the average $16.32 \pm 6.65-\mathrm{d}$ torpor bout durations that male and female little brown bats exhibited during one hibernation season (Reeder et al. 2012), and the average 12.75-d torpor bouts male and female little brown bats used at $5^{\circ} \mathrm{C}$, although considerable individual variation was reported (Twente et al. 1985). Female Indiana bats arousing more often than males is consistent with their higher $\mathrm{MR}_{\mathrm{T}}$ and the theory that arousals are necessitated by some physiological or metabolic imbalance that accumulates during torpor (Willis 1982; Humphries et al. 2003).

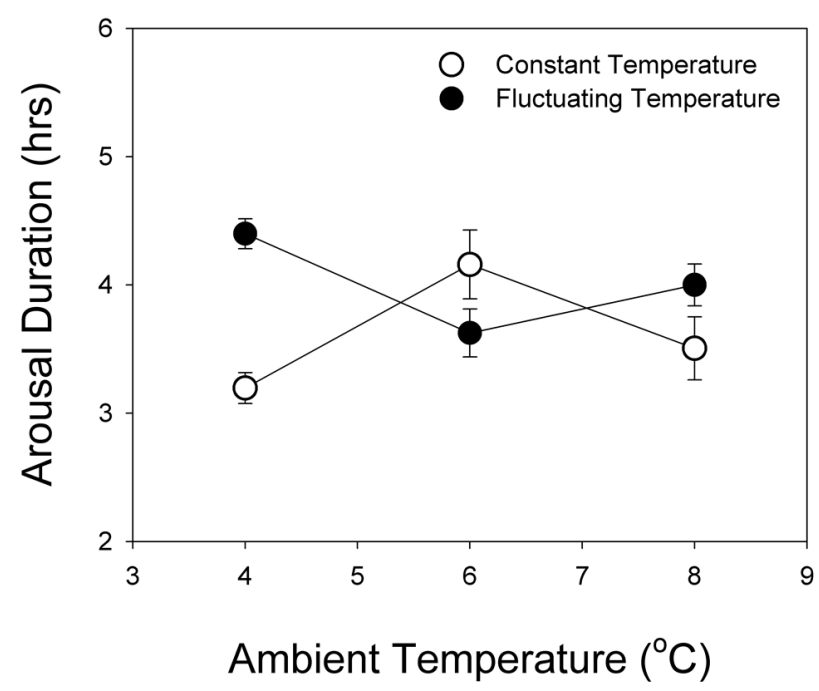

Figure 4. Average hours aroused for female Indiana bats at $4^{\circ}-8^{\circ} \mathrm{C}$ $(n=19)$ at fluctuating and constant temperature treatments. Bats in the fluctuating temperature chamber had longer arousals (repeatedmeasures two-way ANOVA; $P=0.050$ ). Ambient temperature had no effect $(P=0.701)$. 
Table 1: Estimated winter energy budget for Myotis sodalis at selected temperatures

\begin{tabular}{lccc}
\hline & \multicolumn{3}{c}{$T_{\mathrm{A}}$} \\
\cline { 2 - 4 } Variable & $4^{\circ} \mathrm{C}$ & $6^{\circ} \mathrm{C}$ & $8^{\circ} \mathrm{C}$ \\
\hline Arousal duration $(\mathrm{h})$ & 3.20 & 4.16 & 3.51 \\
Aroused metabolism $\left(\mathrm{mL} \mathrm{O}_{2} / \mathrm{h}\right)$ & 60.3 & 61.2 & 69.9 \\
Arousals per season & 10.74 & 29.82 & 27.72 \\
Total kilocalories for arousals (all winter) & 9.994 & 36.644 & 32.799 \\
Torpid per season (h) & 3,566 & 3,476 & 3,503 \\
Metabolism during torpor $\left(\mathrm{mL} \mathrm{O}_{2} / \mathrm{h}\right)$ & .257 & .171 & .325 \\
Total kcal for torpor $($ all winter) & 4.427 & 2.866 & 5.496 \\
Total kcal for arousal and torpor & 14.421 & 39.51 & 38.295 \\
Total fat mass $(\mathrm{g})$ per season & 1.534 & 4.203 & 4.074 \\
\hline
\end{tabular}

Note. The hibernation season was defined as $150 \mathrm{~d}$. Metabolic values $\left(\mathrm{mL} \mathrm{O}_{2}\right)$ were converted into kilocalories $(0.004825$ $\mathrm{kcal} / \mathrm{mL} \mathrm{O}_{2}$ ). Total metabolism ( $\mathrm{kcal}$ ) per season was converted to total fat mass $(9.4 \mathrm{kcal} / \mathrm{g}$ ) per season. These values are underestimates, because no flying occurred during an arousal. Because the ambient temperature $\left(T_{\mathrm{A}}\right)$ used for metabolic rates did not match that used for the skin temperature data, metabolic rates at $1^{\circ} \mathrm{C}$ higher and lower were averaged together when calculating the torpid and arousal metabolic rates at these temperatures. Total hours torpid per season and hours aroused per season (arousal duration and total number of arousals) were calculated from the constant temperature-stability treatment.

The $\mathrm{MR}_{\mathrm{A}}$ is similar at all experimental temperatures (fig. 2), although thermodynamic laws would suggest that arousing from a lower $T_{\mathrm{B}}$ would require more energy than arousing from a higher $T_{\mathrm{B}}$ (larger $\Delta T$ ). Because metabolism during the arousal is so high, the added effect of $T_{\mathrm{A}}$ would appear to be secondary, and the key to reducing total winter energy expenditure is to limit the number of arousals (table 1).

Although there was no difference in the energy cost of an arousal between temperature treatments, $\mathrm{MR}_{\mathrm{A}}$ is at least 200 times higher than $\mathrm{MR}_{\mathrm{T}}$ (table 1). This supports that fact that arousals are energetically expensive (Thomas et al. 1990) and that reducing the number of arousals during hibernation is beneficial to the survival of any hibernating mammal (Speakman and Thomas 2003; Dunbar and Tomasi 2006). Although $\mathrm{MR}_{\mathrm{A}}$ in hibernating bats have not been reported previously, in little brown bats, one arousal was estimated to be equivalent to approximately $65 \mathrm{~d}$ of torpor (Thomas et al. 1990). Using our data for female Indiana bats (table 1), one arousal is estimated to be equivalent to $62 \mathrm{~d}$ of torpor at $6^{\circ} \mathrm{C}$ and $31 \mathrm{~d}$ at $4^{\circ}$ and $8^{\circ} \mathrm{C}$.

Because the duration of an arousal was similar at all experimental temperatures (3-4 h; table 1 ), this suggests that the purpose of an arousal can be met independent of $T_{\mathrm{A}}$. This is similar to the arousal duration of 3-5 h exhibited by male Indiana bats (Dzurick and Tomasi 2008). It is possible that differences in arousal duration might have been revealed if data loggers had collected temperatures at intervals less than $30 \mathrm{~min}$, but most arousals showed a midtemperature during the warming and cooling phases of the arousal, so the arousals were fairly well characterized. Because of the longevity in arousal duration, it is unlikely that a complete arousal occurred within $30 \mathrm{~min}$.

Periodic $T_{\mathrm{A}}$ fluctuations did not alter the basic torpor and arousal pattern of female Indiana bats. However, the significant statistical interaction between $T_{\mathrm{A}}$ and temperature-stability treatment on torpor bout duration suggests a hidden effect, and the data demonstrate differences that are biologically significant (fig. 3). These differences between treatments would translate into more than twice as many arousals over the winter at $6^{\circ}$ and $8^{\circ} \mathrm{C}$. This may be a demonstration of the torpor minimization strategy suggested by Boyles et al. (2007). Although the bats had the fat reserves necessary to do this and survive the hibernation season, and although they may have accrued benefits of reduced torpor, from an energetic perspective, expending this energy on the extra arousals leaves less for migration to their summer habitat and less to contribute to reproductive success.

In addition, our bats in the fluctuating temperature group remained aroused longer, especially at $4^{\circ} \mathrm{C}$. Frequent fluctuations in $T_{\mathrm{A}}$ may cause aroused bats to spend more time attempting to move to another location in the cave that may provide more stable temperatures. Alternatively, frequent fluctuations in $T_{\mathrm{A}}$ may have caused the bats to increase their $\mathrm{MR}_{\mathrm{T}}$, which may increase their need to arouse. It is not known whether hibernating mammals have any flexibility to adjust arousal frequency versus arousal duration to attain the necessary arousal time, and our metabolic data were collected only on bats held at constant $T_{\mathrm{A}}$. Fluctuating $T_{\mathrm{A}}$ also appeared to affect torpid $T_{\mathrm{B}}$, with a higher $T_{\mathrm{SK}}$ in the constant temperature treatment, but we believe this is an artifact attributable to the environmental chamber for this treatment maintaining $0.2^{\circ}-$ $0.3^{\circ} \mathrm{C}$ higher base temperatures (despite being programmed the same).

On the basis of our data, focusing on energetic considerations, Indiana bats should occupy winter hibernacula that provide a mean temperature of $3^{\circ}-6^{\circ} \mathrm{C}$. The upper limit of $6^{\circ} \mathrm{C}$ is based on the lowest $\mathrm{MR}_{\mathrm{T}}$ occurring at $5^{\circ}-7^{\circ} \mathrm{C}$ (fig. 1) and the fewest arousals occurring at $4^{\circ} \mathrm{C}$ (table 1 ). The lower limit of $3^{\circ} \mathrm{C}$ is based on findings that $\mathrm{MR}_{\mathrm{T}}$ starts to increase at $3^{\circ} \mathrm{C}$ in females and on earlier research involving male Indiana bats, which has indicated shorter torpor bouts at $3^{\circ} \mathrm{C}$ (Dzurick and 
Tomasi 2008; fig. 1). We suggest that hibernacula that provide these conditions deserve extra protection.

Metabolic rate data for large Indiana bat clusters are needed to generate a more realistic model for estimating winter energy budgets, but because natural clusters can contain thousands of bats, this is neither feasible nor appropriate for studying individual responses to environmental changes. Nonetheless, the effects of temperature on captive animals may differ from those that may occur under more natural situations. Clustering may provide these bats thermal buffering against fluctuations in $T_{\mathrm{A}}$ or extreme $T_{\mathrm{A}}$. Typically, larger clusters of Indiana bats are found in colder parts of the cave, whereas smaller clusters are found in the warmer parts (Clawson et al. 1980). Although there is no difference between the metabolic rates of individual and small clusters (four individuals) of male Indiana bats (Dzurick and Tomasi 2008), there are few data that address the energetic effects of different sizes and densities of bat clusters. If the Indiana bat population size continues to decrease, smaller clusters would be expected, and laboratory studies investigating individuals or small groups may become more realistic. Finally, studies evaluating the effect of hibernation temperatures on the reproductive success of female Indiana bats will help us understand the observed higher metabolic rates in females as well as provide a better general understanding of the factors that influence the use of torpor in hibernation.

We acknowledge that the optimal hibernation temperature based on energetic considerations may not be the optimum temperature for other aspects of bat ecology and function (e.g., organ function, enzyme function, threat of freezing, speed of arousal upon disturbance, and sperm storage), but these are outside the scope of this study. However, the pervasive nature of energetics in most aspects of life and the general concordance between our results and hibernacula temperatures selected by wild bats, particularly when fat stores are low, indicate that we can use analyses like this to make conservation management decisions.

\section{Acknowledgments}

This research was funded by the US Fish and Wildlife Service, Bat Conservation International, the Missouri State University Graduate College, and the Missouri State University Department of Biology. Assistance in both the field and the laboratory was provided by B. Carney, T. Carter, C. Corben, J. Flinn, J. Layne, K. Livengood, C. Shoults, and B. Steffan. We would like to give a special thanks to C. Dzurick for kindly providing hibernation energetics data for male Indiana bats. Additionally, we would like to thank the anonymous reviewers whose comments helped to strengthen our article.

\section{Literature Cited}

Arant R.J., M.S. Goo, P.D. Gill, Y. Nguyen, K.D. Watson, J.S. Hamilton, J.M. Horowitz, and B.A. Horwitz. 2011. Decreasing temperature shifts hippocampal function from memory formation to modulation of hibernation bout duration in Syrian hamsters. Am J Physiol 301:R438-R447.

Barnes B.M. and D. Ritter. 1993. Patterns of body temperature change in hibernating arctic ground squirrels. Pp. 119-130 in C. Carey, G.L. Florant, B.A. Wunder, and B. Horwitz, eds. Life in the cold: ecological, physiological, and molecular mechanisms. Westview, Boulder, CO.

Blehert D.A., A.C. Hicks, M. Behr, C.U. Meteyer, B.M. Berlowski-Zier, E.L. Buckles, J.T.H. Coleman, et al. 2009. Bat white-nose syndrome: an emerging fungal pathogen? Science 323:227, doi:10.1126/science.1163874.

Bouma H.R., H.V. Carey, and F.G.M. Kroese. 2010. Hibernation: the immune system at rest? J Leukoc Biol 88:619-624.

Boyles, J.G., M.B. Dunbar, J.J. Storm, and V. Brack Jr. 2007. Energy availability influences microclimate selection of hibernating bats. J Exp Biol 210:4345-4350.

Carey C. 1993 . Why do hibernators periodically arouse? overview. Pp. 553-554 in C. Carey, G.L. Florant, B.A. Wunder, and B. Horwitz, eds. Life in the cold: ecological, physiological, and molecular mechanisms. Westview, Boulder, CO.

Clawson R.L., R.K. LaVal, M.L. LaVal, and W. Caire. 1980. Clustering behavior of hibernating Myotis sodalis in Missouri. J Mammal 61:245-253.

Cryan P.M. 2003. Seasonal distribution of migratory tree bats (Lasiurus and Lasionycteris) in North America. J Mammal 84:579-593.

Day K. 2008. Effects of temperature on winter energetics of female Indiana bats (Myotis sodalis). MA thesis. Missouri State University, Springfield.

Dunbar M.B. and T.E. Tomasi. 2006. Arousal patterns, metabolic rate and an energy budget of eastern red bats (Lasiurus borealis) in winter. J Mammal 87:1096-1102.

Dzurick C. and T. Tomasi. 2008. Ambient temperature and the hibernation energy budget of the endangered Indiana bat (Myotis sodalis). Pp. 385-394 in B.G. Lovegrove and A.E. McKechnie, eds. Hypometabolism in animals: hibernation, torpor and cryobiology. Interpak, University of KwaZuluNatal, Pietermaritzburg, South Africa.

Elliott W.R. 2008. Gray and Indiana bat population trends in Missouri. Pp. 46-61 in W.R. Elliott, ed. Proceedings of the 18th National Cave and Karst Management Symposium, St. Louis, Missouri, October 8-12, 2007.

Elliott W.R. and R.L. Clawson. 2001. Temperature data logging in Missouri bat caves. Pp. 52-57 in G.T. Rea, ed. Proceedings of the 1999 National Cave and Karst Management Symposium, Chattanooga, Tennessee, October 19-22, 1999.

French A.R. 1982. Effects of temperature on the duration of arousal episodes during hibernation. J Appl Physiol 52:216220.

Geiser F. 2004. Metabolic rate and body temperature reduction during hibernation and daily torpor. Annu Rev Physiol 66: 239-274.

Geiser F. and G.J. Kenagy. 1988. Torpor duration in relation to temperature and metabolism in hibernating ground squirrels. Physiol Zool 61:442-449.

Hall J.S. 1962. A life history and taxonomic study of the Indiana 
bat, Myotis sodalis. Read Pub Mus Art Gallery Sci Publ 12: $1-68$.

Heller H.C., D.A. Grahn, L. Trachsel, and J. Larkin. 1993. What is a bout of hibernation? Pp. 253-64 in C. Carey, G.L. Florant, B.A. Wunder, and B. Horwitz, eds. Life in the cold: ecological, physiological, and molecular mechanisms. Westview, Boulder, CO.

Henshaw R.E. 1965. Physiology of hibernation and acclimatization in two species of bats (Myotis lucifgus and Myotis sodalis). PhD diss. University of Iowa, Iowa City.

Heusner A.A. 1985. Body size and energy metabolism. Annu Rev Nutr 5:267-293.

Humphrey S.R. 1978. Status, winter habitat, and management of the endangered Indiana bat, Myotis sodalis. Fla Sci 41:6576.

Humphries M.M., D.W. Thomas, and D.L. Kramer. 2003. The role of energy availability in mammalian hibernation: a costbenefit approach. Physiol Biochem Zool 76:165-179.

Humphries M.M., D.W. Thomas, and J.R. Speakman. 2002. Climate-mediated energetic constraints on the distribution of hibernating mammals. Nature 418:313-316.

Jonasson K.A. and C.K.R. Willis. 2011. Changes in body condition of hibernating bats support the thrifty female hypothesis and predict consequences for populations with white-nose syndrome. PLoS ONE 6:e21061, doi:10.1371 /journal.pone.0021061.

Kunz T.H., J.A. Wrazen, and C.D. Burnett. 1998. Changes in body mass and fat reserves in pre-hibernating little brown bats (Myotis lucifugus). Ecoscience 5:8-17.

Kurta A. and T.H. Kunz. 1988. Roosting metabolic rate and body temperature of little brown bats (Myotis lucifugus) in summer. J Mammal 69:645-651.

Lollar A. and B. Schmidt-French. 1998. Captive care and medical reference for the rehabilitation of insectivorous bats. Bat World, Mineral Wells, TX.

Myers R.F. 1964. Ecology of three species of myotine bats in the Ozark Plateau. PhD diss. University of Missouri, Columbia.

Nemeth I. 2012. Assessing the effect of climate change on hibernating mammals using nonlinear mixed effects methods. Pp. 73-84 in T. Ruf, C. Bieber, W. Arnold, and E. Millesi, eds. Living in a seasonal world: thermoregulatory and metabolic adaptation. Springer, New York.

Nicol S., C. Vedel-Smith, and N. Andersen. 2004. Behavior, body temperature, and hibernation in Tasmanian echidnas (Tachyglossus aculeatus). Pp. 149-159 in B.M. Barnes and H.V. Carey, eds. Life in the cold: evolution, mechanisms, adaptation, and application. Institute of Arctic Biology, University of Alaska, Fairbanks.

O'Shea T.J. and D.R. Clark Jr. 2002. An overview of contaminants in bats, with special reference to insecticides and the Indiana bat. Pp. 237-253 in A. Kurta and J. Kennedy, eds. The Indiana bat: biology and management of an endangered species. Bat Conservation International, Austin, TX.

Pretzlaff I. and K.H. Dausmann. 2012. Impact of climatic variation in the hibernation physiology of Muscardinus avellan- arius. Pp. 85-97 in T. Ruf, C. Bieber, W. Arnold, and E. Millesi, eds. Living in a seasonal world: thermoregulatory and metabolic adaptation. Springer, New York.

Quinn G.P. and M.J. Keough. 2002. Experimental design and data analysis for biologists. Cambridge University Press, Cambridge, UK.

Rao P.V. 1998. Statistical research methods in the life sciences. Brooks/Cole, Pacific Grove, CA.

Reeder D.M., C.L. Frank, G.G. Turner, C.U. Meteyer, A. Kurta, E.R. Britzke, M.E. Vodzak, et al. 2012. Frequent arousal from hibernation linked to severity of infection and mortality in bats with white-nose syndrome. PLoS ONE 7:e38920. doi: 10.1371/journal.pone.0038920.

Reid F.A. 2006. Mammals of North America. 4th ed. Houghton Mifflin, New York.

Richter A.R., S.R. Humphrey, J.B. Cope, and V. Brack Jr. 1993. Modified cave entrances: thermal effects on body mass and resulting decline of endangered Indiana bats (Myotis sodalis). Conserv Biol 7:407-415.

Speakman J.R. and P.A. Racey. 1989. Hibernal ecology of the pipistrelle bat: energy expenditure, water requirements and mass loss, implications for survival and the function of winter emergence flights. J Anim Ecol 58:797-813.

Speakman J.R. and D.W. Thomas. 2003. Physiological ecology and the energetics of bats. Pp. 430-490 in T.H. Kunz and M.B. Fenton, eds. Bat ecology. University of Chicago Press, Chicago.

Thomas D.W. 1995. Hibernating bats are sensitive to nontactile human disturbance. J Mammal 76:940-946.

Thomas D.W. and D. Cloutier. 1992. Evaporative water loss by hibernating little brown bats, Myotis lucifugus. Physiol Zool 65:443-456.

Thomas D.W., M. Dorais, and J.-M. Bergeron. 1990. Winter energy budgets and cost of arousals for hibernating little brown bats, Myotis lucifugus. J Mammal 71:475-479.

Timpone J.C. 2004. Roost site selection of bats in northeast Missouri with emphasis on the endangered Indiana bat (Myotis sodalis). MA thesis. Missouri State University, Springfield.

Turner G.G., D.M. Reeder, and J.T.H. Coleman. 2011. A fiveyear assessment of mortality and geographic spread of whitenose syndrome in North American bats and a look to the future. Bat Res News 52:13-27.

Tuttle M.D. and J. Kennedy. 2002. Thermal requirements during hibernation. Pp. 68-78 in A. Kurta and J. Kennedy, eds. The Indiana bat: biology and management of an endangered species. Bat Conservation International, Austin, TX.

Twente J.W., J. Twente, and V. Brack Jr. 1985. The duration of the period of hibernation of three species of vespertilionid bats. II. Laboratory studies. Can J Zool 63:2955-2961.

Twente J.W. Jr. 1955. Some aspects of habitat selection and other behavior of cavern-dwelling bats. Ecology 36:706-732.

US Fish and Wildlife Service (USFWS). 2007. Indiana bat ( $M y$ otis sodalis) draft recovery plan: first revision. USFWS, Fort Snelling, MN.

—. 2011. 2011 rangewide population estimate for the Indiana 
bat (Myotis sodalis) by USFWS Region. http://www.fws.gov /midwest/Endangered/mammals/inba/pdf /2011inbaPopEstimate04Jan12.pdf.

Weltzin M.M., H.W. Zhao, K.L. Drew, and D.J. Bucci. 2006. Arousal from hibernation alters contextual learning and memory. Behav Brain Res 167:128-133.
Willis J.S. 1982. The mystery of the periodic arousal. Pp. 92103 in C.P. Lyman, J.S. Willis, A. Malan, and L.C.H. Wang, eds. Hibernation and torpor in mammals and birds. Academic Press, New York.

Withers P.C. 2001. Design, calibration and calculation for flowthrough respirometry systems. Aust J Zool 49:445-461. 